\title{
The Support for Repairing the Main Roadway in Mine under Complicated Conditions
}

\author{
Kun Zhang, Jian-xi Ren, Song Wang \\ Xi'an University of Science \& Technology, Xi'an, 710054, China
}

KEYWORD: Complicated conditions; Repairing roadway; FLAC Simulation; Monitoring; Leaving in flexible cushion for combined yield supporting

ABSTRACT: Based on Weijiadi mine No.2 cross-cut West water storage repairing engineering, through on-site investigation, theoretical analysis, FLAC numerical simulation, field tests and monitoring metheds to study The Supporting Technology for Repairing the Main Roadway in Mine under Complicated Conditions, the leaving in flexible cushion for combined yield supporting technology for repairing the main roadway in mine under Complicated Conditions is proposed. Field test and Monitoring showed that bolt-grouting and leaving in flexible cushion for combined yield supporting can give full play to the surrounding rock deformation, and improve the surrounding rock carrying capacity of the joint body, repairing roadway support project is reasonable to good effect.

\section{Introduction}

With the increasing depth of mine, the research on reasonable supporting technology of deep rock becomes more and more important (e.g. Qian Qihu, 2004. The current development of nonlinear rock mechanic the mechanical problems of deep rock mass; HeManchao, et al , 2005. Deep soft rock supporting technology of the repair project for transport tunnel in Liuhai Coal Mine ). Because of complex conditions which are high deep, soft rock, large deformation, the dynamic pressure, mine roadways often encounter supporting problem (e.g. Wang Lianguo et al, 2005. Study on mechanisms and technology for bolting and grouting in special soft rock roadways under high stress. Many roadways are repaired repeatedly). It not only wastes resources, but also often brings hidden troubles for the safety production of coal min. Finding scientific and reasonable repair method and the suitable supporting method is a technical problem for coal mine. For roadway is coal mine. This paper studies repairing project of No.2 crosscut west water storage in Weijiadi mine. The purpose is to provide a reference for similar roadway repairing problem.

\section{Analysis damage characteristics of No.2 crosscut west water storage}

The depth of Weijiadi coal mine is 620 meters, which belongs to the category of deep rock mass. West mining area is affected by $2 \#$ syncline structure, and coal seam is syncline seam. No.2 cross-cut is located in the western area, and it is the main rail transport of mine. It is along the floor. It is a small distance from 103 goaf and 104 goaf, which are in the upper part of No. 2 crosscut. So the crosscut transportation lane is located in the stress concentration zone. The west water storage is located in third layer coal. The original support is bolting, and the second support is $U$ type steel frame. At present, the top and sides of roadway crack severely, and floor heaves greatly, and the roadway deformation is serious. They affect the normal safety production seriously. No.2 crosscut west water storage has been repaired repeatedly, which not only make the cost of supporting increase greatly, but also directly affect the safety production. Because of deep burring, high stress, mined goaf, mine pressure severe appearance, unreasonable layout of mining area, coal pillar width and unreasonable position (Figure 1), the unreasonable supporting form, the No.2 crosscut west water storage breaks and repairs repeatedly. At present, the most serious damage areas at the original designation size is $3.7 \mathrm{~m} \times 4.8 \mathrm{~m}$, which dimension is $9.0 \mathrm{~m}^{2}$; while now the roadway becomes $2.0 \mathrm{~m} \times 1.8 \mathrm{~m}$, and dimension is $2.0 \mathrm{~m}^{2}$.

The repaired section of No. 2 crosscut west water storage in Weijiadi coal mine passes through third layers of coal (Figure 2). According to the properties of surrounding rock, it will be divided into four sections, which are the first character part (rock section), second character part (the upper 
is rock, the under is coal), third character part (coal section) and fourth character part (the upper is coal, the down is rock).

For the analysis of characteristics of surrounding rock, the paper adopts borehole camera to do loosing range test. The results show that: (1) the loose range of the first feature segment (whole rock segment) is $3.5 \sim 4.5 \mathrm{~m}$, the loose range of the second feature segment is $3 \sim 4 \mathrm{~m}$, the third is $6.3 \sim 7.2 \mathrm{~m}$, and the fourth is 4.9 5.8m; (2) The loose circle test shows that, the loose range of the first feature segment (whole rock segment) is the smallest, and the third is the maximum. The middle loose ranges of surrounding rock are second and fourth feature segment. Compares the loose range between the second and fourth segment, the fourth feature segments is larger than second segment (coal rock segment).

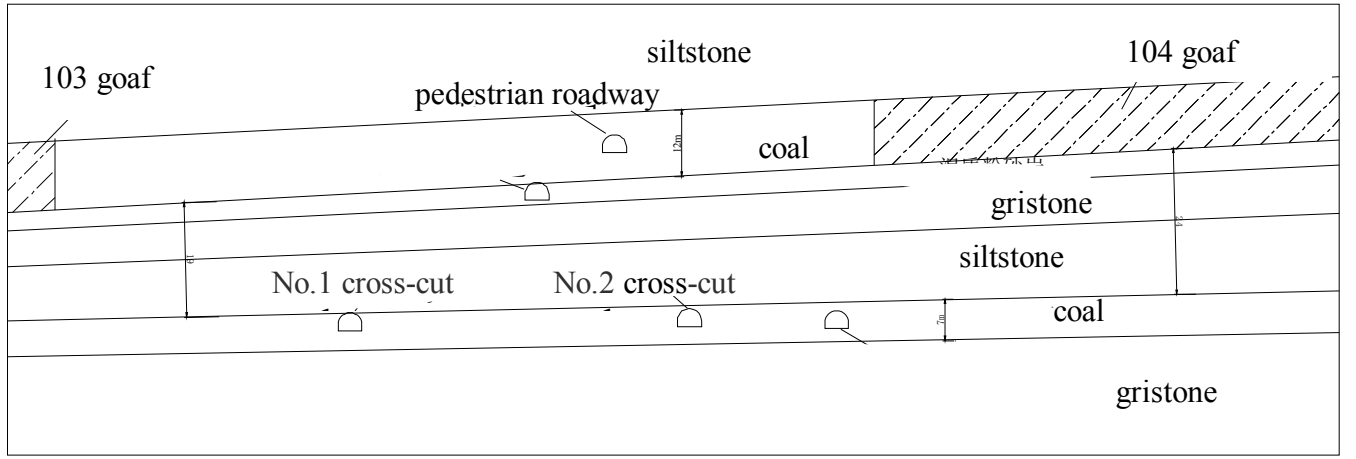

Fig.1 Goaf Distribution around the No.2 cross-cut

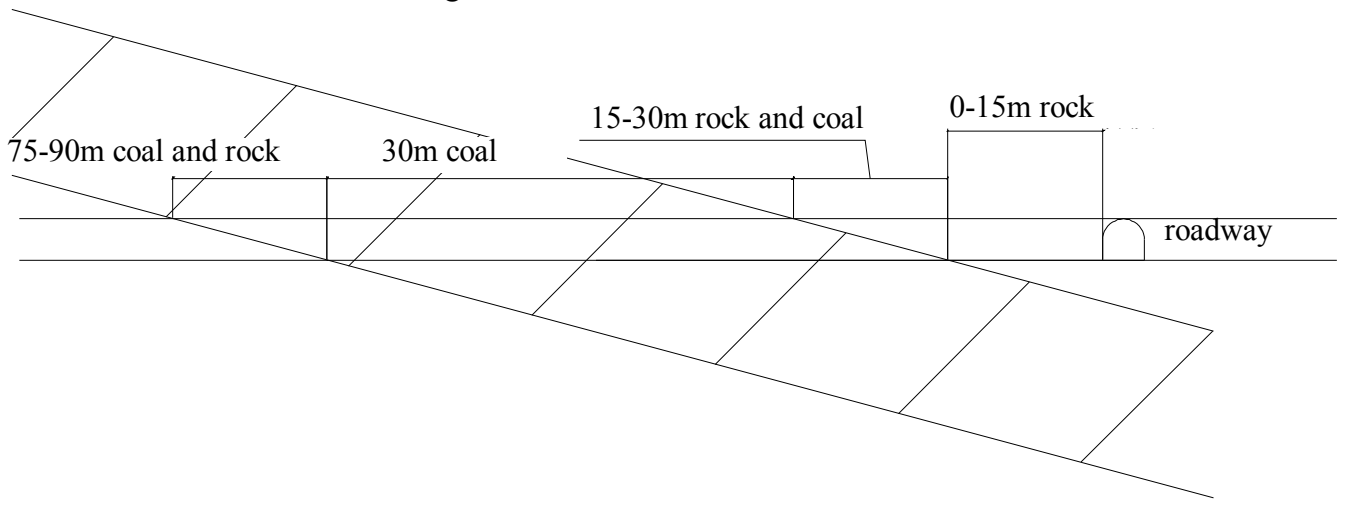

Fig.2 Geological profile of No.2 cross-cut West water storage repairing section

\section{Repair support scheme}

The supporting scheme is anchor cable and $U$ type steel shed before the original supporting scheme failed. The surrounding rock occurs repeatedly broken deformation. Rock fissure develops greatly. It grouts easily. So the first support adopts bolting and grouting methods, which will improve the residual strength and integrity of the surrounding rock. Bolting can achieve full length anchoring, and can improve the bearing capacity of surrounding rock, and can reduce the load on the support. It will maximize the self bearing capacity of surrounding rock and the stability of the roadway. The second support is the reserved flexible cushion and steel. It is a combined support scheme (Figure 3). The soft cushion pressure combined support technology is a new development of rigid flexible layer supporting technology. The rigid gap flexible layer will be made of special flexible material for filling. It will leave releasing place and releasing holes in the rigid body. Rigid flexible layer support technology has the supporting characteristics, and the pressure release is more uniform and gentler. 


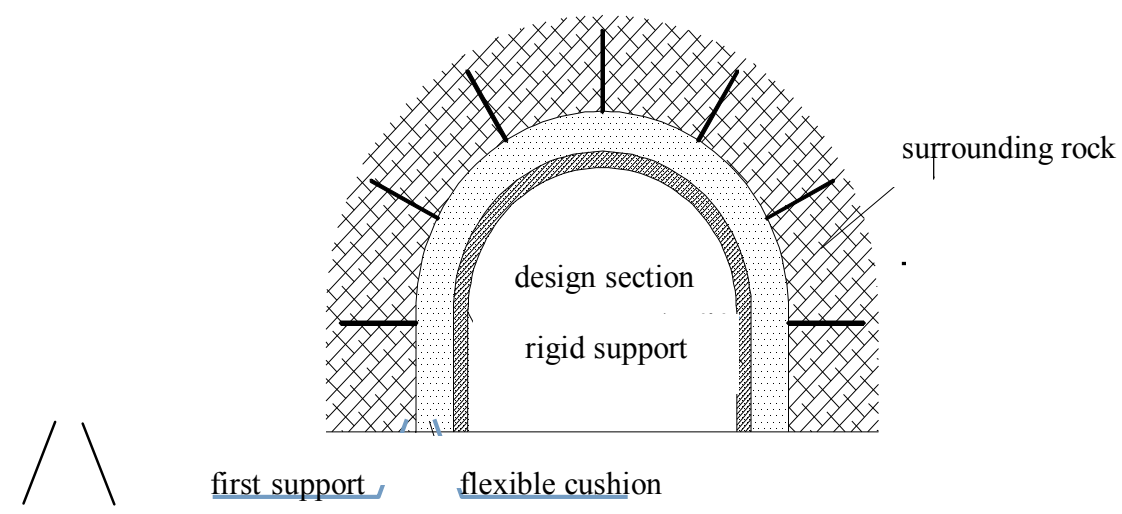

Fig.3 Mechanical schematics for the Leaving in flexible cushion for combined yield supporting

Due to the different surrounding rock conditions of Repair sections, the support parameters of each section are not same. Taking into the worst damage section account, the paper focuses on this section. Because of the large loose range, the roadway combines grouting method with short pipe and long pipe. The anchor length is $2600 \mathrm{~mm}$ in coal section; The anchorage spacing is $700 \mathrm{~mm} *$ $700 \mathrm{~mm}$. The cable length is $10000 \mathrm{~mm}$; The cable spacing is $1900 \mathrm{~mm} * 1400 \mathrm{~mm}$. The length of short pipe is $2800 \mathrm{~m}$; the grouting space is $1700 \mathrm{~mm} * 1400 \mathrm{~mm}$. The length of long pipe is $9000 \mathrm{~mm}$, and its spacing is $2600 \mathrm{~mm} * 2800 \mathrm{~mm}$. The spacing of $U$ type steel in roof is $800 \mathrm{~mm}$, and bottom beam spacing is $400 \mathrm{~mm}$. The concrete is C30 grade, and the diameter of reinforced steel is $14 \mathrm{~mm}$. Bolt locks bottom beaming, and dry sand fills soft cushion.

\section{FLAC simulation of the deformation regularity}

Before the repair project implement, the software simulate the construction scheme with FLAC3D. The paper analyses stability of the roadway according to the simulation results. It studies feasibility of the repair project, and it predicts deformation, and it provides reference for reasonable design of monitoring program.

\section{Establishment of the model}

Figure 3 is the measured curve of freezing pressure, from the curve we can see that the range of freezing pressure is $30.69 \sim 696.87 \mathrm{KPa}$.

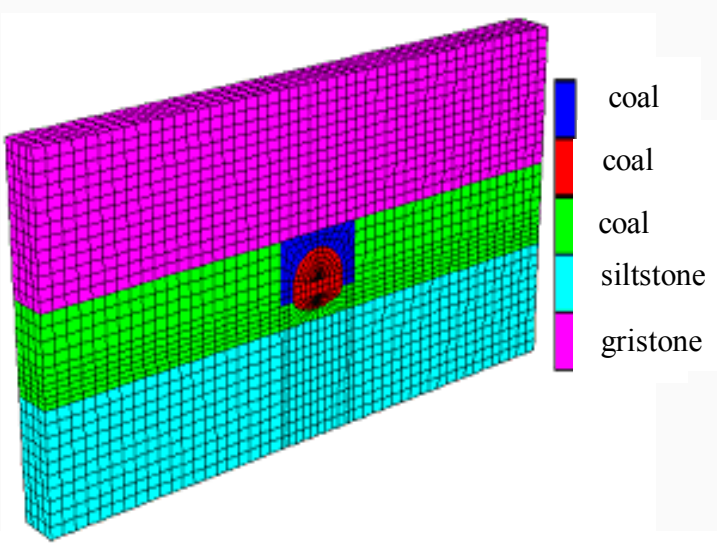

Fig.4 model diagram

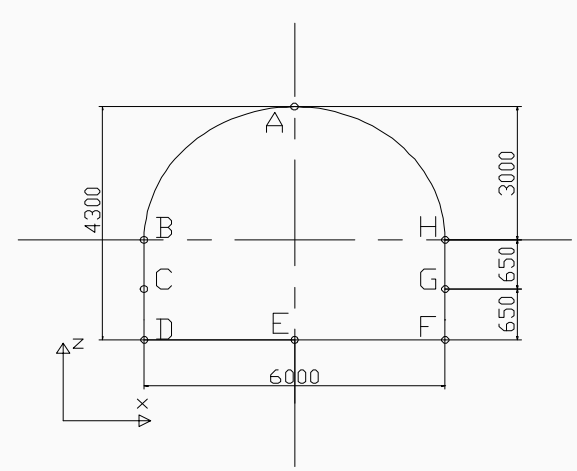

Fig. 5 monitoring points layout of surrounding rock displacement in Roadway

Numerical simulation analyses on coal segment. The model size is $60 \mathrm{~m} * 4 \mathrm{~m} * 32 \mathrm{~m}$, and it has a total of 6960 units and 14536 nodes. It takes normal constraint around the bottom and fixed constraints in the end (Figure 4). The floor is coarse sand rock. The model thick is $11 \mathrm{~m}$, and coal seam thick is $8 \mathrm{~m}$. The roof rock is siltstone, and its thick is $13 \mathrm{~m}$. It sets the 8 key points in the section (Figure 5). 


\section{Analysis of numerical calculation results}

The combined support structure with first support and second support is shown in Figure 6 . After the implementation of the program, roadway surface displacement is shown in figure 7 , and the displacement calculation values of monitoring points are shown in table 1.

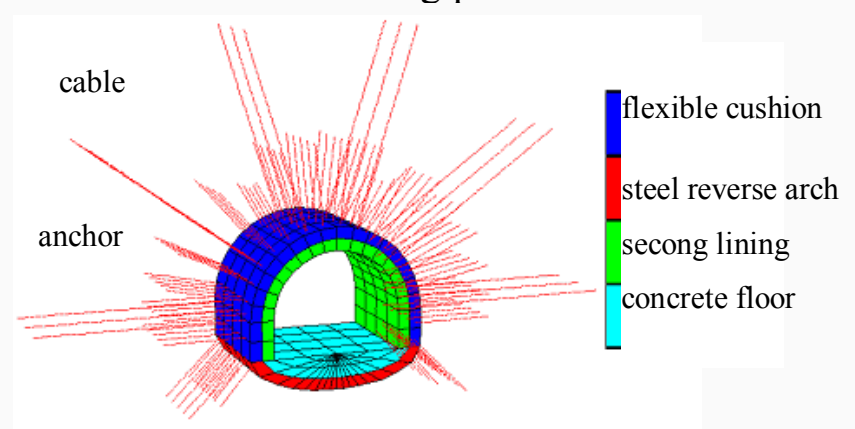

Fig.6 support structure after excavation

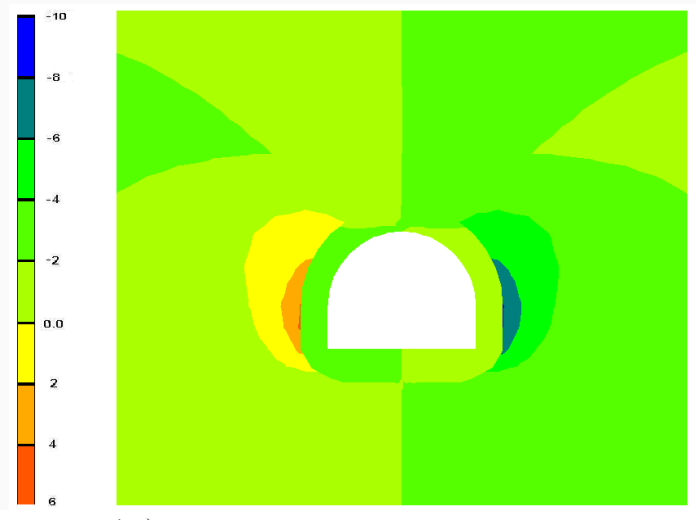

(a) level displacement contour(unit: $\mathrm{mm}$ )

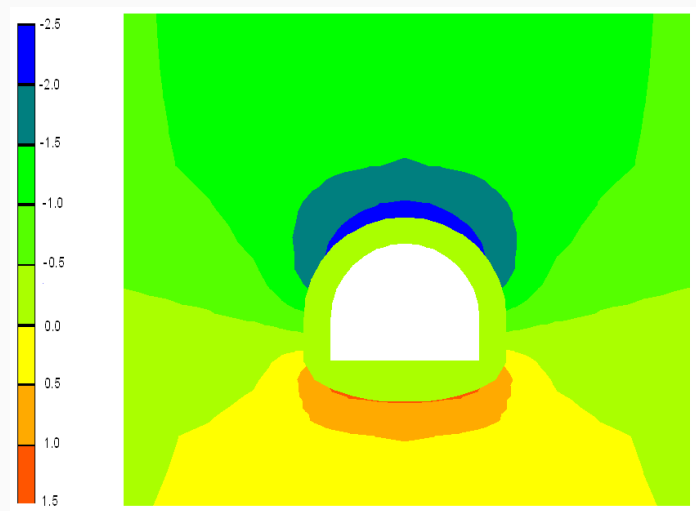

(b) vertical displacement contour(unit: $\mathrm{mm}$ )

Fig. 7 combined support roadway surface displacement contour

Table 1 The key point displacement in Roadway combination support (unit: $\mathbf{m m}$ )

\begin{tabular}{ccccccccc} 
Key poins & & & & & & & \\
Support conditions & A & B & C & D & E & F & G & H \\
\hline First support & -12.6 & 85.2 & 77.3 & 79.5 & 19 & -79.5 & -77.3 & -85.2 \\
Combined support & -3.2 & 4.4 & 3.7 & 3.1 & 4.6 & -3.1 & -3.7 & -4.4 \\
\hline
\end{tabular}

Through the analysis of Figure 7 and table 1, we can know that after first support, the deformation of roof and floor is severer than sides. The largest settlement of sides is in the 3/4 of straight wall, and roof subsidence and heave is in the center of the roadway. While under second support, the displacement in top and side greatly reduces. It fully meets the requirements of engineering. Plastic deformation area becomes smaller; especially the floor heave phenomenon has 
been controlled goodly. Therefore, the design of the combined support scheme is feasible, and it can effectively control the deformation of roadway.

\section{Analysis of the monitoring results}

In the implementation of program, each section sets 1 monitoring sections. It is total 4 monitoring sections. Under the first support, the program main monitors roof separation, surface displacement, roadway bolt (cable) force. Under second support, the program mainly monitors surface displacement of rigid layer. Third monitoring section is at $52 \mathrm{~m}$, which is in the whole coal area, and it was monitored for 54 days.

\section{Analysis of roof separation data}

The roof separation is monitored by multi-point displacement meter. It can monitor 4 points of the roof. The positions were located in $1.0 \mathrm{~m}, 2.8 \mathrm{~m}, 4.5 \mathrm{~m}, 6.9 \mathrm{~m}$ from roadway roof. We can see from figure 8: the roof is relatively stable. There are significant changes in the thirtieth day, which shows that burst pressure period is about 30 days.

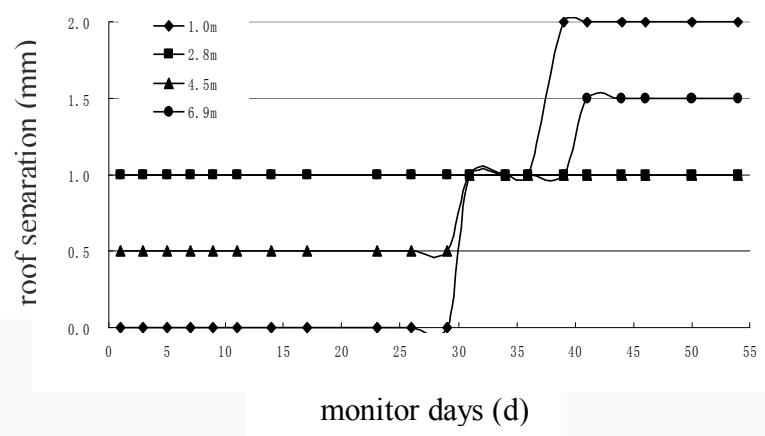

Fig. 8 the roof separation of the third monitoring section

\section{Analysis of roadway surface displacement data}

Figure 9 shows: the roadway deformation rate decreases, the roadway deformation tends to be stable. After grouting surrounding rock, roof subsidence and two sides deformation are well controlled. So we can see the importance of the grouting in the surrounding rock.

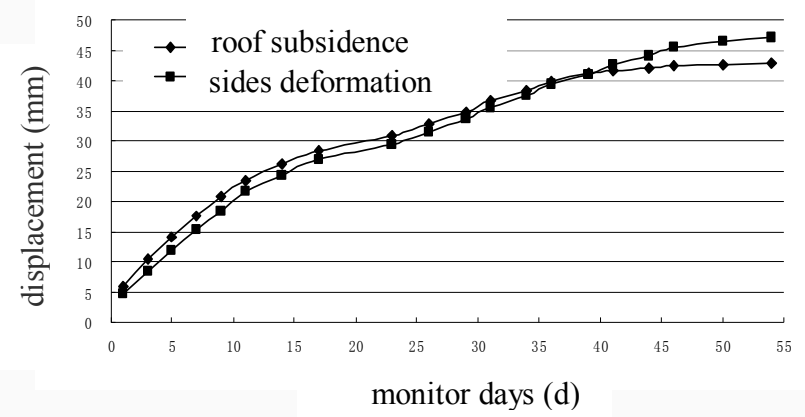

Fig.9 roadway surface displacement of the third monitoring section

\section{Bolt (cable) analysis of stress state}

From Figure 10 and Figure 11, we can kwon that: anchor (cable) force changes greatly in tenth day and fortieth day, which is grouting time. After this, the force is stable. The top pressure is greater than sides, and the right pressure is greater than left pressure. This is due to the 1070 roadway on the right side. 


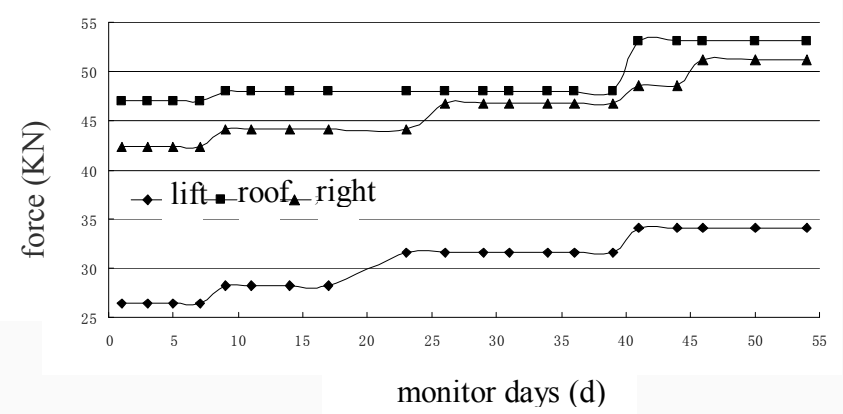

Fig. 10 anchor force of the third monitoring section

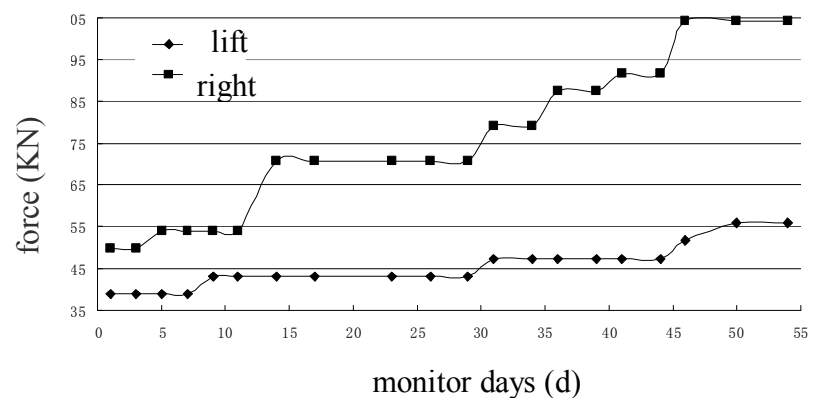

Fig.11 Cable force of the third monitoring section

\section{Analysis on the surface displacement of steel reinforced concrete}

In the implementation of the second supporting scheme, we begin monitors displacement of the steel reinforced concrete. The 1 4 steel reinforced concrete is in coal segment. Therefore we focus on the analysis of these monitoring dates.

The surface displacement of steel reinforced concrete is monitored for 20 days. You can see from Figure 12, the force of side is greater than the roof, which illustrates the surrounding rock stress transfer from the roof to the periphery after the first support. The stress distribution is more uniform; surrounding rock is subjected to the rigid support. So it has characteristics of compression and compaction in the first 10 days, then the deformation rate tends to be slow. This process is also the stress distribution of surrounding rock. And it is the change from single bearing to sharing for rock and supporting scheme.

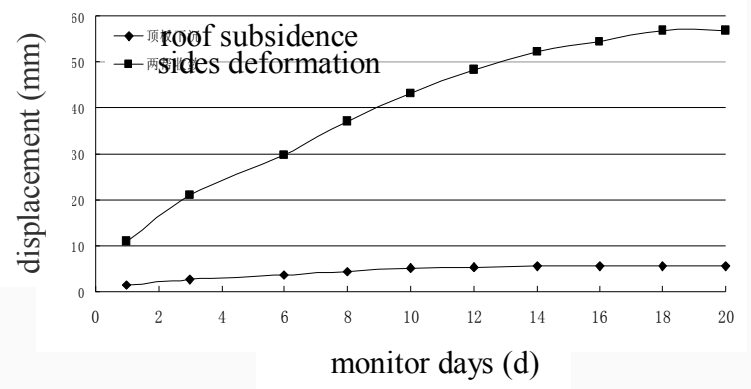

Fig.12 Roadway surface displacement of the second monitoring section

\section{Stress analysis of steel reinforced concrete}

In the area of the first four steel reinforced concrete, we bury 5 steel stress meters. They monitor the stress state of steel reinforced concrete. We can see from Figure 13, the roadway is basically stable under the first support and stress of steel reinforced concrete is smaller under the second support. 


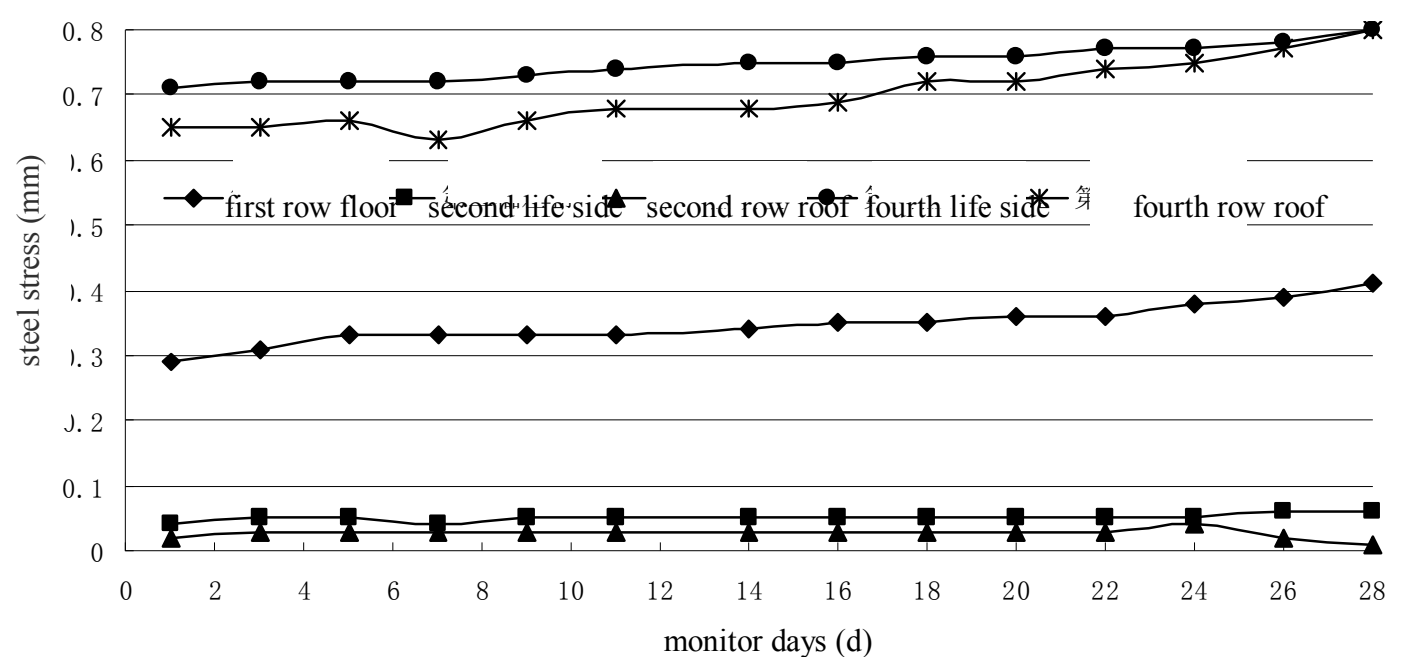

Fig.13 Reinforcement force of the second monitoring section

From the analysis of the monitoring data, we can see that: the deformation of whole coal is not large, and it gradually stabilizes. This is due to the proper scheme, which plays a significant effect on surrounding rock.

\section{conclusion}

(1) The paper use combined methods with field investigation and theoretical analysis to determine the loose range of surrounding rock, which provides an important reference for determining the length of the anchor and bolt.

(2) Through the FLAC numerical simulation calculation and field monitoring data, the paper shows the grouting plays a positive role in improving the strength of broken rock mass. It can change the anchoring state from point to full length anchoring. It also can make the loose rock to form a whole. It makes stress distribution of the surrounding rock more uniform and increases the self bearing capacity.

(3) Based on the theory of rigid gap flexible layer supporting, the paper put forward Leaving in flexible cushion for combined yield supporting theory. It points that sand or proper gradation pebbles fills surrounding the gap. It gives full place to play the role of the flexible cushion. It makes concentration pressure of the surrounding rock distribute uniformly in the rigid support.

(4) Monitoring data shows that, the grouting result with tow times are better than one time for repeatedly broken rock. Leaving in flexible cushion for combined yield supporting makes soft rock deform fully. It makes the surrounding rock and support play combined action.

(5) For complex conditions of soft rock roadway, the scheme of grouting and leaving flexible cushion for combined yield supporting is feasible, and the effect is good.

\section{References}

[1] Qian Qihu, 2004. The current development of nonlinear rock mechanic themechanical problems of deep rockmass[A].Chinese Society for Rock Mechanics and Engineering. Proceedings of the 8th Rock Mechanics and Engineering Conference[C]. Beijing: Science Press: $10-17$.

[2] HeManchao, GuoZhibiao, RenAiwu, eta.1, 2005. Deep softrock supporting technology of the repair project for transport tunnel in Liuhai Coal Mine[J]. Chinese Journal of Geotechnical Engineering, 27 (9): 977-980

[3] Wang Lianguo, Li Mingyuan, Wang Xuezhi, 2005. Study on mechanisns and techology for bolting and grouting in special soft rock roadways under high stress[J].Chinese Journal of Rock Mechanics and Engineering, 24(16): 2 889-2 893.

[4] LIU Quan-sheng,ZHANG Hua,LIN Tao, 2004. Study on Stability of Deep Rock Roadways in Coal Mines and Their Support Measures[J]. Chinese Journal of Rock Mechanics and Engineering, 23 (21): 3732-3737 
[5] HOU Chao-jiong, GOU Pan-feng, 2000. Mechanism Study on Strength Enhancement for the Rocks Surrounding Roadway Supported by Bolt[J]. Chinese Journal of Rock Mechanics and Engineering, 19(3):342-345..

[6] KONG De-sen, JIANG Jin-quan, 2000. Stability analysis of deep roadway in structural stress field[J]. Ground Pressure and Strata Control,17(4):56-58.

[7] HUA Xin-zhu, XIE Guang-xiang, ZHENG Gao-sheng, 2002. Repair technology, monitoring and analysis for ultra soft rock failed mine roadway[J]. Coal Science and Technology, 30 (5):22-23.

[8] YANG Chao, LU Shiliang, JIANG Yaodong, 2000.Controlling effects of support resistant roadway deformation for different rocks[J].Journal of China University of Mining and Technology, 29(2): 170-173.(in Chinese).

[9] BAI Jian-biao, WANG Xiang-yu, JIA Ming-kui, 2008. Theory and application of supporting in deep soft roadways[J]. Chinese Journal of Geotechnical Engineering,30(5):632-633 